\title{
ASSESSMENT OF NOMINAL SHEAR STRENGTH OF REINFORCED CONCRETE COLUMN
}

\author{
Dea Fauziah Larasati $^{1}$, Harun Alrasyid ${ }^{1 *}$, Data Iranata ${ }^{1}$
}

\begin{abstract}
SNI 2847-2019 and ACI 318-19 have regulated the use of materials in the design of shear strength, such as limitation on the compressive strength of concrete and reinforcement. The difference of the regulation model and limitation material affects the evaluation of the nominal shear strength of Reinforced Concrete (RC) columns. This assessment investigates the evaluation of $R C$ columns database experimental from several researchers. The various experimental data are consist of normal to high strength RC columns with a total of 162 specimens. The specimens database of RC columns provides a variety of concrete compressive strength, yield strength, axial-load ratio, shear reinforcement ratio, and aspect ratio of a column with numerous parameters. This study aims to evaluate the formula of shear strength of RC columns according to SNI and ACI, and other experimental models. Both the SNI and ACI have two different concrete nominal shear strength equations. The results from the evaluations show that the simplified SNI and the detailed ACI are more conservative compared to other nominal shear strength equations. The detailed SNI has less conservative, conversely, the simplified ACI has a good precision under the maximum limit of material used. Moreover, the size effect modification factor $\left(\lambda_{s}\right)$ is included in detailed ACI for evaluating the concrete shear strength of RC Columns. The results show that the utilization of the size effect modification factor is not affected because the value is close to 1 .
\end{abstract}

Keywords: Reinforced concrete, column, SNI, ACI

\section{INTRODUCTION}

The structure of RC columns are usually constructed without considering the modern seismic design codes in the low to moderate zones. These typical non-seismically detailed RC columns have widely spaced shear reinforcement, which vulnerable to shear failure. Hence, for existing RC columns, an assessment of shear strength $\mathrm{RC}$ columns is needed to mitigate shear failure as per building code requirements. The latest SNI 2847-2019 [1] is referred to the previous edition ACI 318-14, whereas the latest edition ACI 318-19 [2] is slightly different from the SNI 2847-2019 [1]. To avoid shear failure of Reinforced Concrete (RC) columns under the combination of gravity and earthquake load, the nominal shear strength must be higher than the nominal shear due flexural strength of the column [11]. The SNI 2847 [1] and ACI 318 [2] propose that the nominal shear strength of the column is the summation of the shear strength of concrete and the shear strength of steel the summation of the shear strength of concrete and the shear strength of steel. The nominal shear strength of the column of ACI dan SNI can be seen as follows:

$$
V_{n}=V_{c}+V_{s}
$$

Where $V_{n}=$ nominal shear strength, $V_{c}=$ nominal shear strength provided by concrete, and $V_{s}=$ nominal shear strength provided by shear reinforcement. Equation (1) is one-way shear equations for non-prestressed concrete. This equation is concerned on the components of the structure. In the component of the structure without shear reinforcement, shear strength is resisted by the concrete. However, with shear reinforcement, the nominal shear strength is assumed by concrete and shear reinforcement. This nominal shear strength of the RC columns has several materials strength. For concrete, the maximum compressive strength is $70 \mathrm{MPa}$ for both SNI 2847 [1] and ACI 318 [2]. For transverse reinforcement, the maximum yield strength is

${ }^{1}$ Civil Engineering Department of Institut Teknologi Sepuluh Nopember, Surabaya, Indonesia

Corresponding author email address: harun@ce.its.ac.id
$420 \mathrm{MPa}$ for SNI 2847 [1] and $550 \mathrm{MPa}$ for ACI 318 [2]. When determining the concrete shear strength of RC Columns the size effect modification factor $\left(\lambda_{s}\right)$ is also considered at ACI 318 [2]. However, this size effect modification factor is not considered at SNI 2847 [1].

Over the last century, according to several experts, the use of high strength materials in RC columns has been studied extensively [3]-[11]. However, the actual use of high strength $\mathrm{RC}$ columns material is not accommodated by the two codes. Hence, it is essential to evaluate the use of normal strength and high strength at two regulations either SNI 2847 [1] or ACI 318 [2].

This assessment shows experimental observations on 162 shear-critical RC columns were collected from the literature. This study aims to evaluate the formula of shear strength of RC columns which is according to SNI 28472019 [1], ACI 318-19 [2], and other experimental models such as Sezen 2002 [12] and Alrasyid 2015 [11]. Therefore, the results of this study will obtain the correlation between the experimental and predict strengths that related to the shear strength of RC columns.

\section{RESEARCH SIGNIFICANCE}

This study investigates the evaluation of the nominal shear strength of RC columns with a total of 162 specimens. The specimens database of RC columns provides a variety of concrete compressive strength, yield strength, axial-load ratio, shear reinforcement ratio, and aspect ratio of a column with numerous parameters. These specimens are compared with several models [1], [2], [11], [12]. However, there are few differences between evaluating these models on shear strength such as formula equation and material strength used. The evaluation results can show the ratio of measured shear strength to the nominal shear strength of RC columns. The results of this study believe that the ratio of each evaluated shear strength from different models can provide information on which models are comparatively conservative. 


\section{METHODOLOGY}

Prior to the analysis, the sets of shear test data of RC columns from available experiments were first collected. The summarized details of these RC columns are shown in Table 1 and the parameters used as shown in Table 2. The corresponding various experimental data are consist of normal to high strength RC columns. Furthermore, the experimental database was used to analyze the nominal shear strength of RC columns within step-by-step equations of nominal shear strength that expressed in equations (2-18). Moreover, this study is also evaluating the nominal shear strength using maximum materials strength limits. The maximum limit for concrete compressive strength is $70 \mathrm{MPa}$ for both SNI 2847 [1] and ACI 318 [2] and for transverse reinforcement, the maximum yield strength is $420 \mathrm{MPa}$ for SNI 2847 [1] and $550 \mathrm{MPa}$ for ACI 318 [2].

As previously mentioned, the shear strength evaluation from several models produces the ratio of measured shear strength to the nominal shear strength of RC columns, $V_{\text {test }} / V_{n}$. Furthermore, from these ratios, it can be defined the mean ratio and the coefficient of variation of shear strength RC columns which each corresponds to SNI 2847 [1], ACI 318 [2], and other experimental models such as Sezen 2002 [12] and Alrasyid 2015 [11].

Table 1 Shear Failure of RC Column Database Experimental

\begin{tabular}{|c|c|c|}
\hline No. & Researchers & $\begin{array}{c}\text { Number of } \\
\text { Columns }\end{array}$ \\
\hline 1 & Lynn (2001) [13] & 8 \\
\hline 2 & Sezen (2002) [12] & 3 \\
\hline 3 & Umehara and Jirsa (1982) [14] & 3 \\
\hline 4 & Bett et al. (1985) [15] & 1 \\
\hline 5 & Xiao and Martirossyan (1998) [16] & 2 \\
\hline 6 & Ousalem (2006) [17] & 12 \\
\hline 7 & Nakamura and Yoshimura (2002) [18] & 4 \\
\hline 8 & Nakamura and Yoshimura (2003) [18] & 6 \\
\hline 9 & Yoshimura et al. (2003) [18] & 3 \\
\hline 10 & Ramirez and Jirsa (1980) [19] & 2 \\
\hline 11 & Wight and Sozen (1973) [20] & 12 \\
\hline 12 & Saatcioglu and Ozcebe (1989) [20] & 2 \\
\hline 13 & Yalcin (1997) [21] & 1 \\
\hline 14 & Ikeda (1968) [22] & 7 \\
\hline 15 & Umemura and Endo (1970) [23] & 9 \\
\hline 16 & Kokusho (1964) [24] & 2 \\
\hline 17 & Kokusho and Fukuhara (1965) [25] & 2 \\
\hline 18 & Sakaguchi et al. (1990) [6] & 6 \\
\hline 19 & Maruta (2008) [26] & 14 \\
\hline 20 & Takami and Yoshioka (1997) [27] & 6 \\
\hline 21 & Takaine et al. (2010) [28] & 4 \\
\hline 22 & Kuramoto and Minami (1992) [29] & 6 \\
\hline 23 & Aoyama (2001) [4] & 8 \\
\hline 24 & Shinohara et al. (2008) [30] & 5 \\
\hline 25 & Akihiko et al. (1990) [31] & 6 \\
\hline 26 & Sibata (1997) [32] & 5 \\
\hline 27 & Yu Chen Ou (2015) [10] & 14 \\
\hline \multirow[t]{2}{*}{28} & Harun Alrasyid (2015) [11] & 9 \\
\hline & Total Specimens & 162 \\
\hline
\end{tabular}

\section{A. EXPERIMENTAL DATABASE OF SHEAR FAILURE COLUMNS}

An experimental database of 162 shear-critical RC columns from 28 researchers has been considered in this study, and the summarized details of these RC columns are shown in Table 1.

Table 2 RC Columns Database Experimental Parameter

\begin{tabular}{lc}
\hline \multicolumn{1}{c}{ Parameters } & Ranges \\
\hline Concrete compressive strength $\left(f_{c}{ }^{\prime}\right)$ & $13.1-205 \mathrm{MPa}$ \\
Ratio of longitudinal reinforcement $\left(\rho_{l}\right)$ & $0.19-4.4 \%$ \\
Yield strength of longitudinal & $324-1106 \mathrm{MPa}$ \\
reinforcement $\left(f_{y l}\right)$ & $0.07-1.9$ \\
Ratio of shear reinforcement $\left(\rho_{\mathrm{t}}\right)$ & $315.6-1450 \mathrm{MPa}$ \\
Yield strength of shear reinforcement $\left(f_{y t}\right)$ & $0.04-0.36$ \\
Gross area of column section $\left(m^{2}\right)$ & $1.01-4.03$ \\
Aspect ratio of column $(\mathrm{a} / \mathrm{d})$ & \\
\hline
\end{tabular}

As can be seen from Table 2, the various experimental data consist of normal to high strength RC columns; therefore, in Table 2 for example in concrete compressive strength, $f_{c}$ ' have 13.1-205 $\mathrm{MPa}$, et al. These all-experimental database used to calculate the nominal shear strength of RC columns.

Fig. 1 shows that normalized shear strength decreases with the increasing shear span-to-depth ratio within the range of test data considered. Fig. 2 shows the relationship between the normalized shear strength and the axial-load ratio. The data trend shows that shear strength increases with an increasing axial-load ratio.

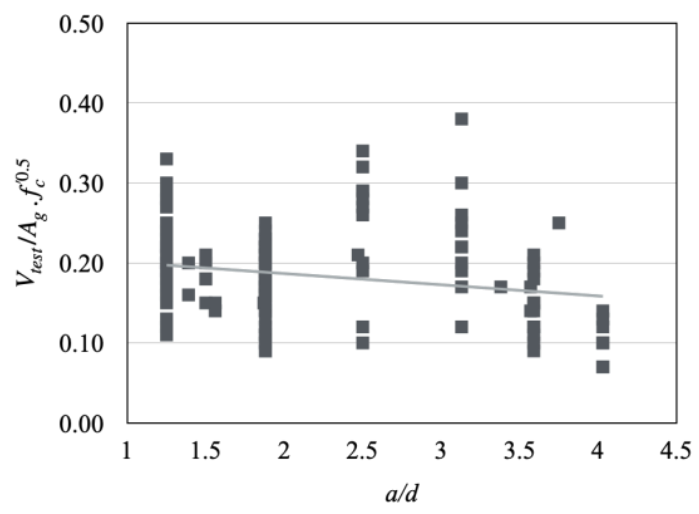

Figure 1 Normalized shear strength versus shear span-todepth ratio

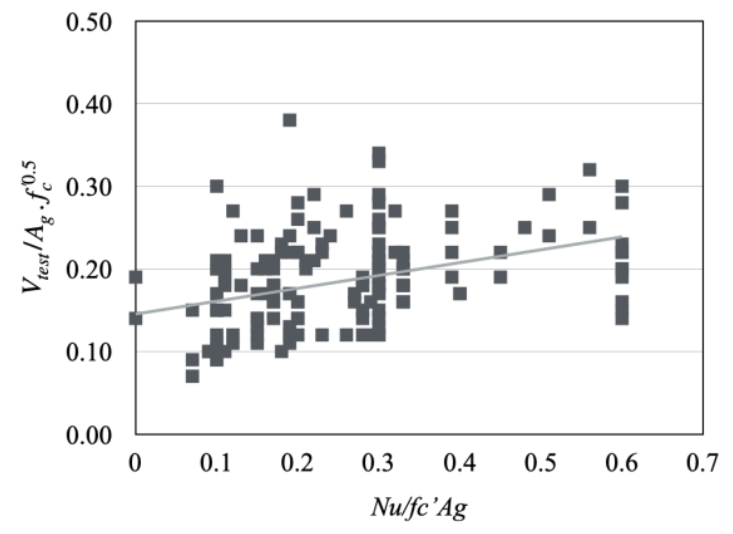

Figure 2 Normalized shear strength versus axial-load ratio

\section{B. ANALYSIS THE AVERAGE FORMULA TEST}

The nominal shear strength of RC column is the summation of shear strength of concrete and the shear strength of steel. After knowing the results of the calculations, the ratio of measured shear strength to the nominal shear strength of 
RC columns is obtained. This section explained the formula used on the code of each model [1][2][11][12].

\section{B. 1 SNI 2847-2019}

The evaluation begins by determining the nominal shear strength provided by concrete $V_{c}$ according to Eq. (2-3):

$$
\begin{gathered}
V_{c, S N I 1}=0.17\left(1+\frac{N_{u}}{14 A_{g}}\right) \lambda \sqrt{f_{c}{ }^{\prime}} b_{w} d \\
V_{c, S N I 2}=0.29 \lambda \sqrt{f_{c}{ }^{\prime}} b_{w} d \sqrt{1+\frac{0.29 N_{u}}{A_{g}}}
\end{gathered}
$$

A reinforced concrete member with axial compression, $V_{c}$ can be determined with simplified equations, Eq (2) and detailed equation Eq (3). The contribution of transverse reinforcement to shear can be expressed as Eq. (4):

$$
V_{s}=\frac{A_{v} f_{y t} d}{s}
$$

Hence, there is two concrete nominal shear strength, the summation of shear strength of concrete and shear strength of steel are expressed as Eq. (5-6):

$$
\begin{aligned}
& V_{n, S N I 1}=V_{c, S N I 1}+V_{s} \\
& V_{n, S N I 2}=V_{c, S N I 2}+V_{s}
\end{aligned}
$$

\section{B. 2 ACI $318-19$}

For non-prestressed members, $V_{c}$ with $\mathrm{A}_{\mathrm{v}} \geq \mathrm{A}_{\mathrm{v}, \text { min }}$ shall be calculated according to $\mathrm{Eq}(7)$ and $\mathrm{A}_{\mathrm{v}} \geq \mathrm{A}_{\mathrm{v}, \min }$ according to Eq (8) as follows:

$$
\begin{gathered}
V_{c, A C I 1}=\left[0.17 \lambda \sqrt{f_{c}{ }^{\prime}}+\frac{N_{u}}{6 A_{g}}\right] b_{w} d \\
V_{c, A C I 2}=\left[0.66 \lambda_{s} \lambda\left(\rho_{w}\right)^{1 / 3} \sqrt{f_{c}{ }^{\prime}}+\frac{N_{u}}{6 A_{g}}\right] b_{w} d
\end{gathered}
$$

ACI 318 [2] the reinforced concrete member with axial compression can be determined with simplified equations, Eq (7) and detailed equation Eq (8). However, in the ACI 318 [2] for $V_{c, A C I 2}$, it is necessary to consider the effect size modification factor $\lambda_{s}$, which is expressed as

$$
\lambda_{s}=\sqrt{\frac{2}{1+0.004 d}} \leq 1
$$

Same as the previous model, the nominal shear strength provided by shear reinforcement $V_{s}$ used equation Eq (4). Furthermore, the nominal shear strength RC column, $V_{n}$ shall be calculated by:

$$
\begin{aligned}
& V_{n, A C I 1}=V_{c, A C I 1}+V_{s} \\
& V_{n, A C I 2}=V_{c, A C I 2}+V_{s}
\end{aligned}
$$

\section{B.3 SEZEN'S MODEL 2002}

In the Sezen model, the nominal shear strength provided by concrete, , $V_{c}$, is considered the effect of ratio $a / d$, as follows:

$$
V_{c, \text { sezen }}=k\left(\frac{0.5 \sqrt{f c^{\prime}}}{a / d} \sqrt{1+\frac{N_{u}}{0.5 A_{g}}}\right) 0.8 A_{g}
$$

Whereas, the shear strength of shear reinforcement, $V_{s}$, is calculated using Eq (13):

$$
V_{s, \text { sezen }}=k \frac{A_{v} f_{y t} d}{s}
$$

The nominal shear strength model proposed by Sezen [12] is a summation of the contribution of shear strength of concrete and steel.

$$
V_{n, \text { sezen }}=V_{c, \text { sezen }}+V_{s, \text { sezen }}
$$

\section{B.4 ALRASYID'S MODEL 2015}

The concrete shear strength, $V_{c}$, is considered the reduction factor, $\alpha$ in the Alrasyid model [11] can be estimated as follows:

$$
V_{c, \text { alrasyid }}=0.29 \alpha \sqrt{f_{c}{ }^{\prime}} b_{w} d \sqrt{1+\frac{2 N_{u}}{\alpha \sqrt{f_{c}{ }^{\prime} b_{w} d}}}
$$

Where $\alpha$ is the reduction factor by Eq (16-17):

$$
\alpha=\left(1-0.85 \sqrt{\frac{N_{u}}{\sqrt{f_{c}^{\prime} A_{g}}}}\right)
$$

for

$$
0 \leq \frac{N_{u}}{f_{c}{ }^{\prime} A_{g}} \leq 0.6
$$

The summation of shear strength of concrete and shear strength of steel is expressed as

$$
V_{n, \text { alrasyid }}=V_{c, \text { alrasyid }}+V_{s}
$$

Furthermore, all the results of $V_{n}$ calculations from several models produce the ratio of measured shear strength to the nominal shear strength of RC columns, $V_{\text {test }} / V_{n}$.

\section{ANALYSIS AND DISCUSSIONS}

A compiled experimental database of 162 RC columns was used to evaluate the popular models from SNI 2847 [1], ACI 318 [2], and other experimental models such as Sezen 2002 [12] and Alrasyid 2015 [11]. Table 3 tabulates the ratio of measured shear strength to the nominal shear strength, as explained before. Table 3 provides evaluations of normal strength, high strength and the combination both of normal and high strength RC columns. According to the evaluations, it can be seen that the results have been evaluated twice within the data and the maximum limit. Thus, all evaluations are obtained the mean and the coefficient of variation.

The coefficient of variation $(\mathrm{CoV})$ is a statistical measure of the dispersion of data points in a data series around the mean. The coefficient of variation represents the ratio of the standard deviation to the mean, and it is a beneficial statistic for comparing the degree of variation from one data series to another. The smaller the CoV value, the more accurate the data is. Conversely, the higher value of $\mathrm{CoV}$, the less accurate the data level of variation is. However, the 


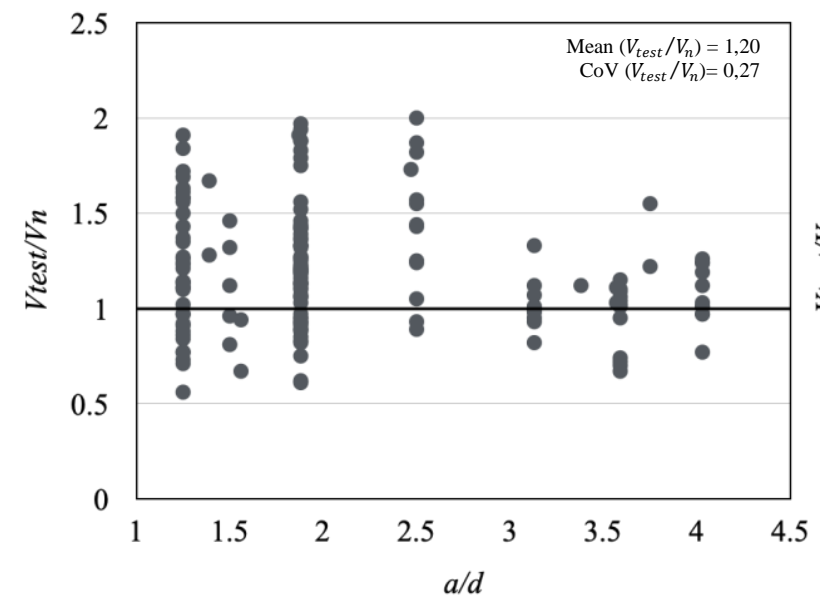

(a) Method in SNI 2847-2019 $V_{n, S N I 1}$ according to existing data

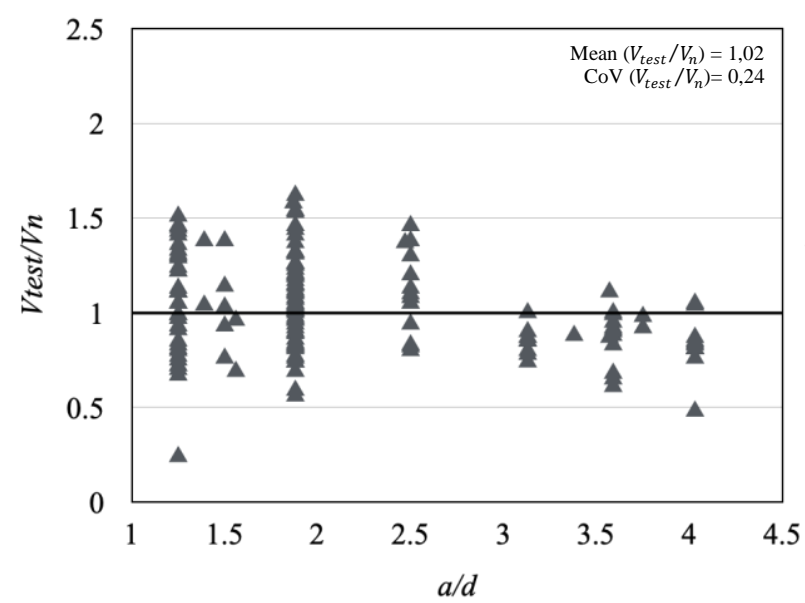

(c) Method in ACI 318-19 $V_{n, A C I 1}$ according to existing data

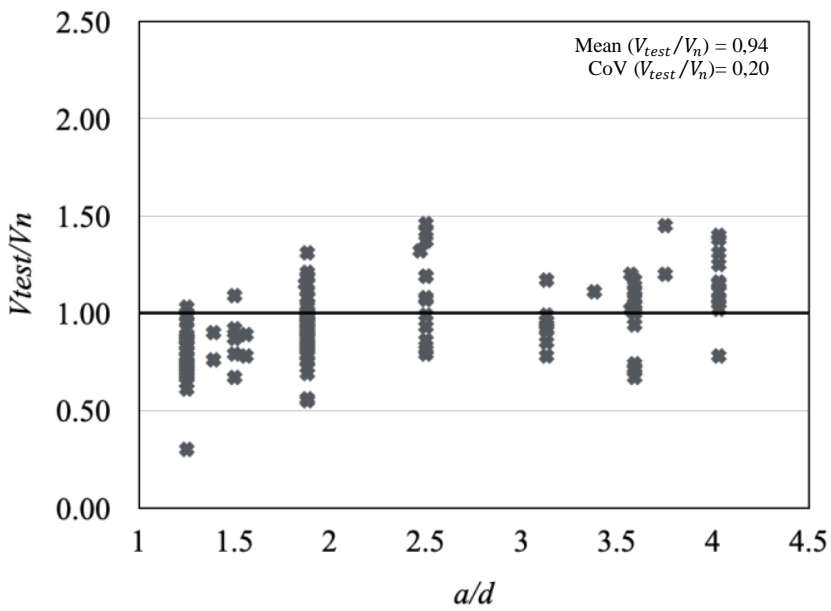

(e) Method in Sezen's Model $V_{n, \text { sezen }}$ according to existing data

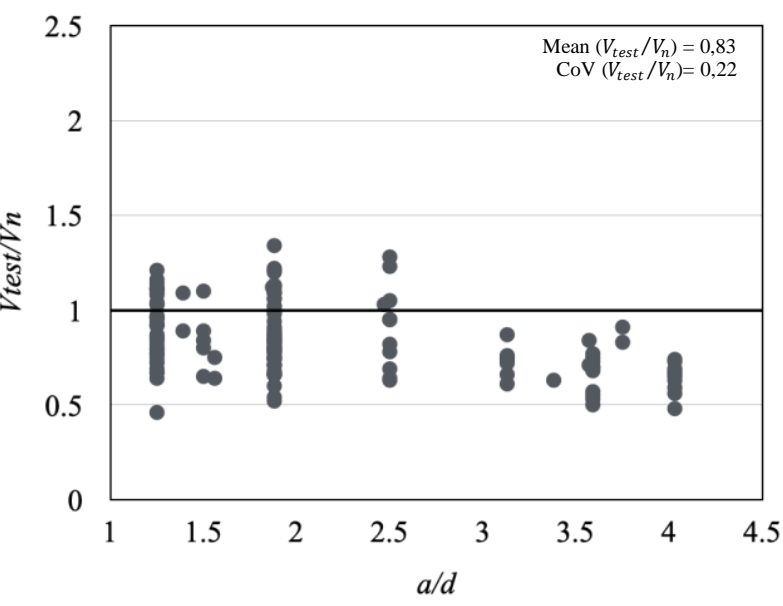

(b) Method in SNI 2847-2019 $V_{n, S N I 2}$ according to existing data

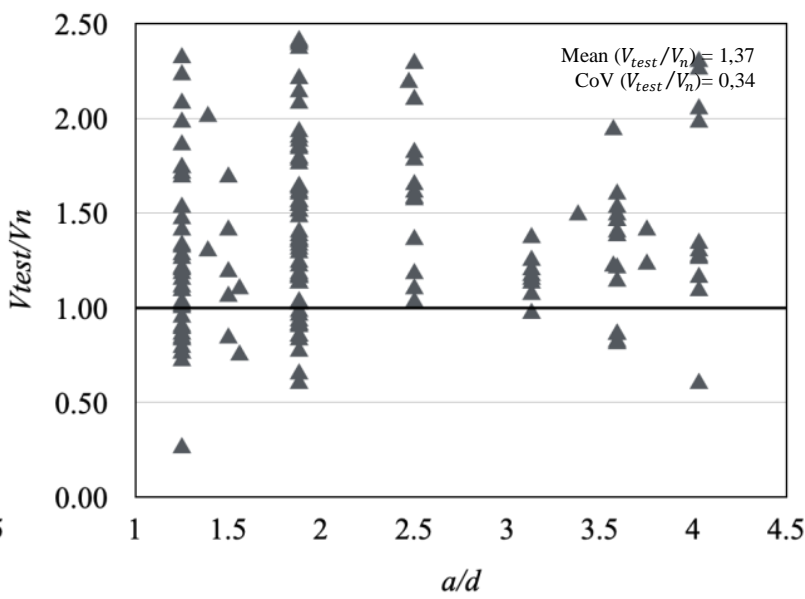

(d) Method in ACI 318-19 $V_{n, A C I 2}$ according to existing data

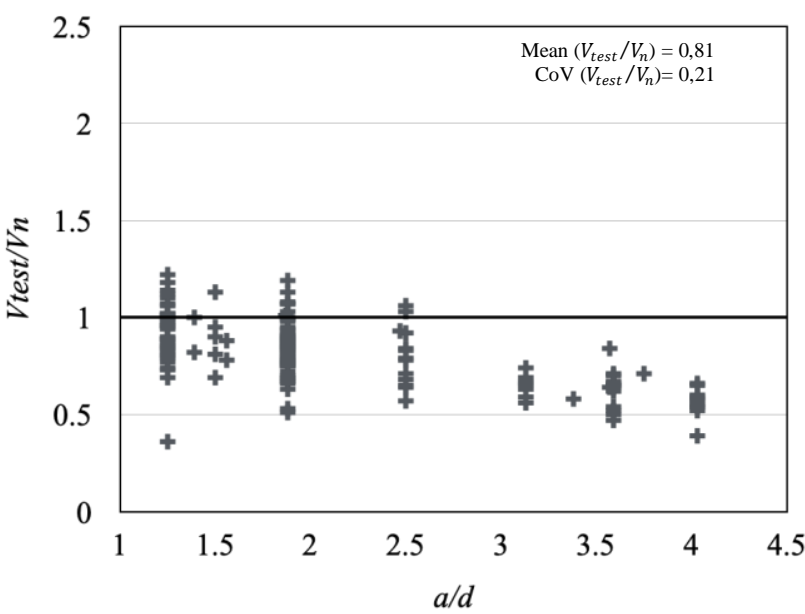

(f) Method in Alrasyid's Model $V_{n \text {,alrasyid }}$ according to existing data

Figure 3. Variations of measured to calculated strength ratio versus shear span-to-depth ratio according to existing data: (a) Method in SNI 2847-2019 $V_{n, S N I I}[1]$; (b) Method in SNI 2847-2019 $V_{n, S N I 2}$ [1]; (c) Method in ACI 318-19 $V_{n, A C I I}$ [2]; (d) Method in ACI 318-19 $V_{n, A C I 2}$ [2]; (e) Method in Sezen's Model $V_{n, \text { sezen }}$ [12]; (f) Method in Alrasyid's Model $V_{n, \text { alrasyid }}[11]$ 


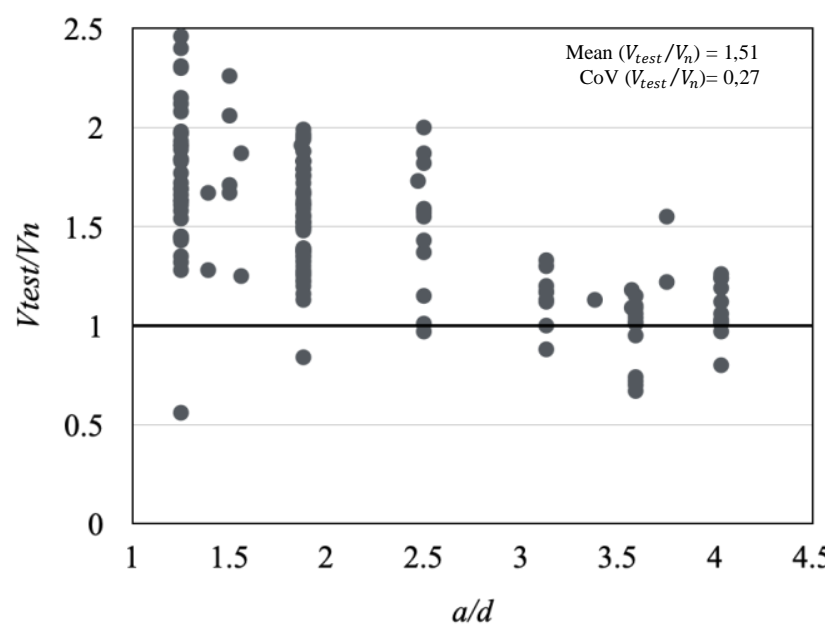

(a) Method in SNI 2847-2019 $V_{n, S N I 1}$ according to maximum limit

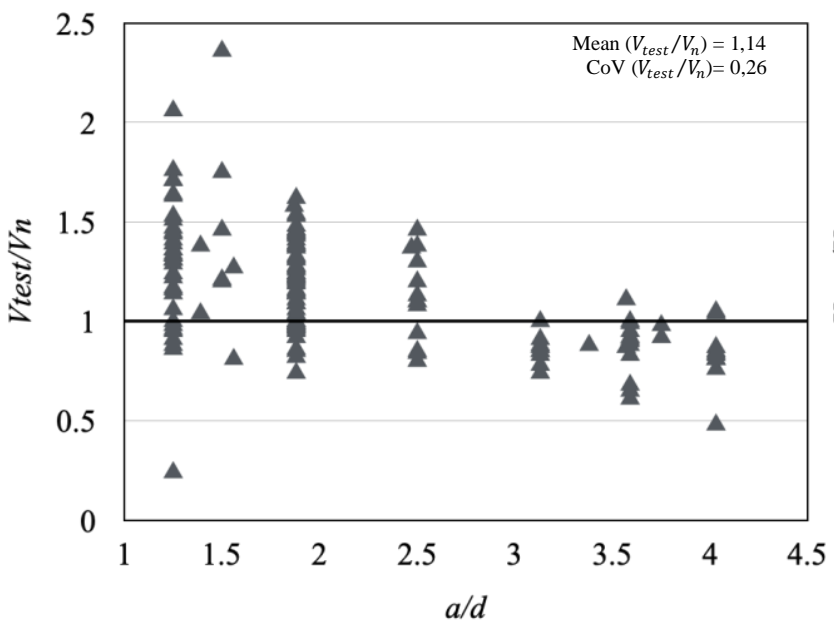

(c) Method in ACI 318-19 $V_{n, A C I 1}$ according to maximum limit

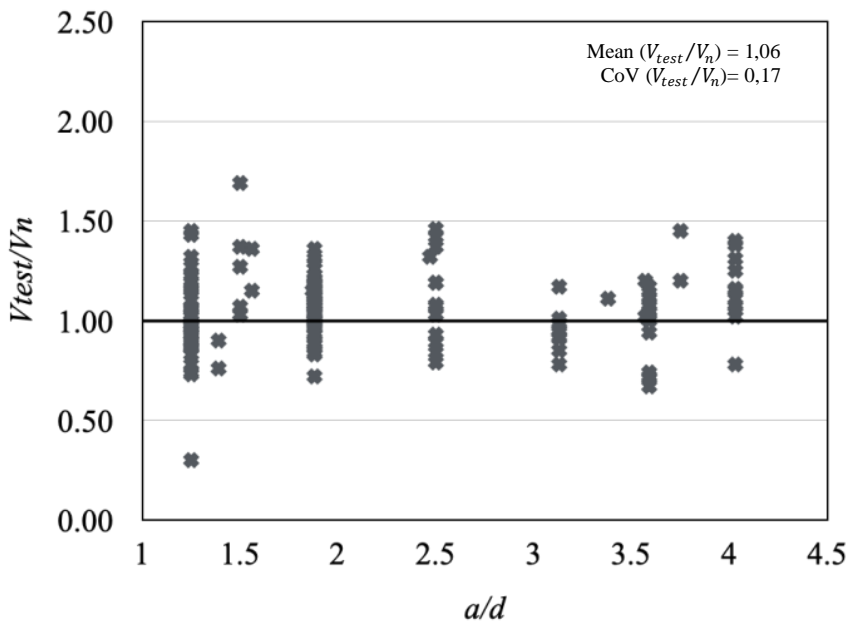

(e) Method in Sezen's Model $V_{n \text {,sezen }}$ according to maximum limit

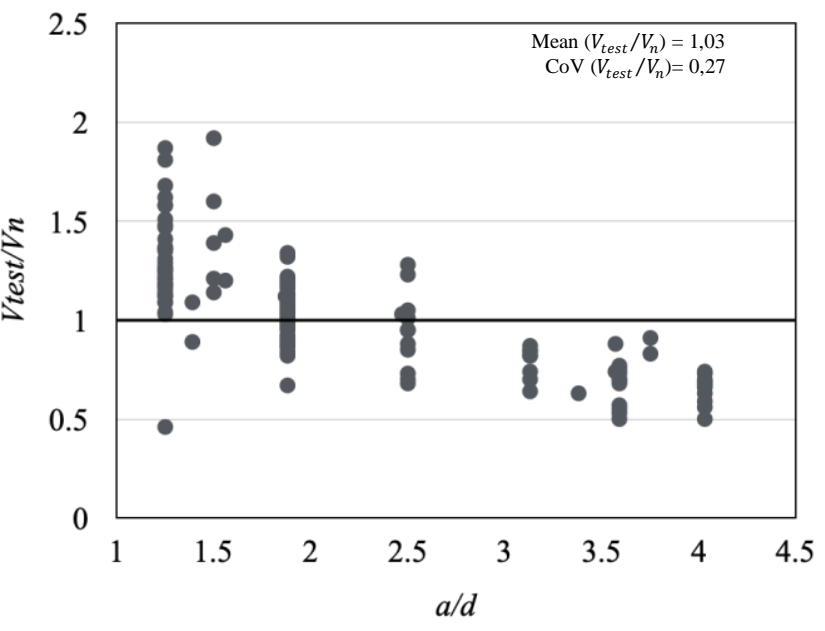

(b) Method in SNI 2847-2019 $V_{n, S N I 2}$ according to maximum limit

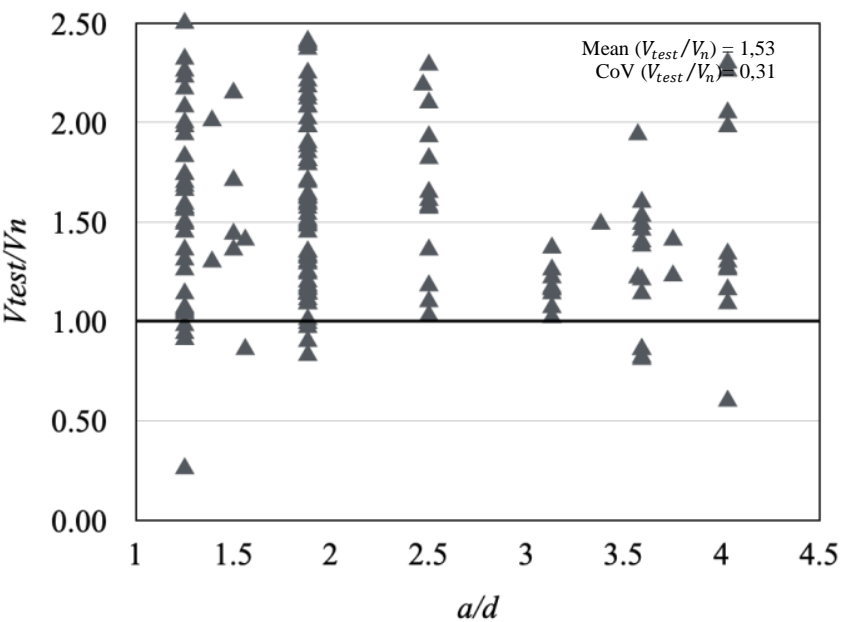

(d) Method in ACI 318-19 $V_{n, A C I 2}$ according to maximum limit

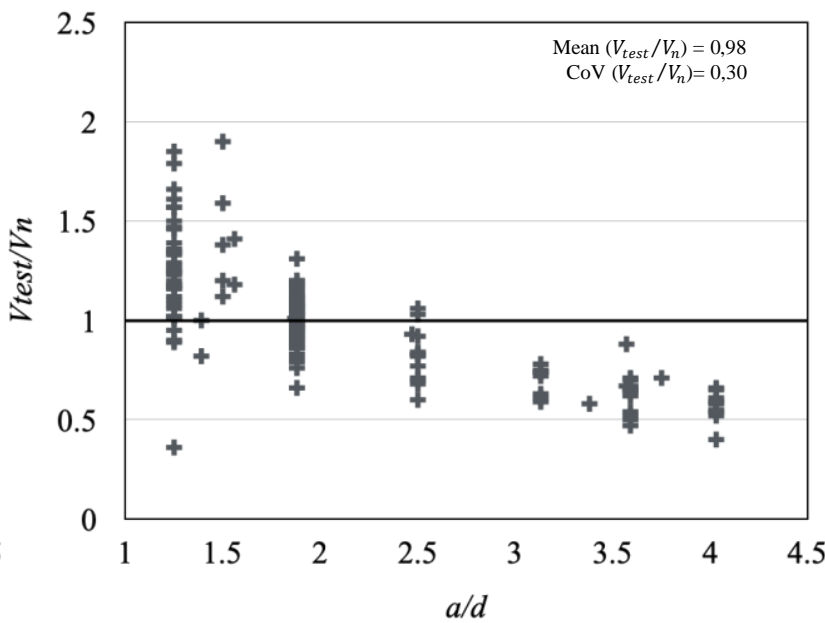

(f) Method in Alrasyid's Model $V_{n \text {,alrasyid }}$ according to maximum limit

Figure 4.Variations of measured to calculated strength ratio versus shear span-to-depth ratio according to maximum limit: (a) Method in SNI 2847-2019 $V_{n, S N I I}$ [1]; (b) Method in SNI 2847-2019 $V_{n, S N I 2}$ [1]; (c) Method in ACI 318-19 $V_{n, A C I 1}$ [2]; (d) Method in ACI 318-19 $V_{n, A C I 2}$ [2]; (e) Method in Sezen's Model $V_{n, \text { sezen }}$ [12]; (f) Method in Alrasyid's Model $V_{n \text {,alrasyid }}$ [11] 


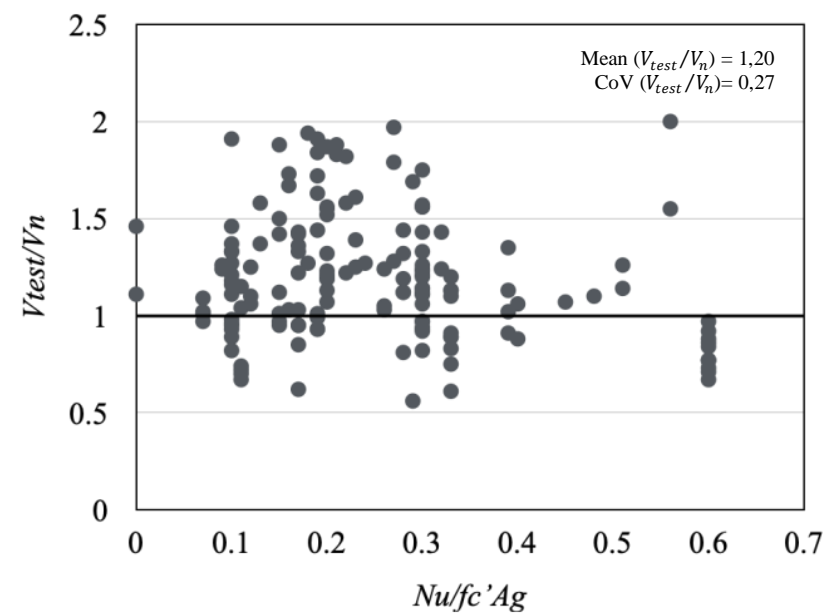

(a) Method in SNI 2847-2019 $V_{n, S N I 1}$ according to existing data

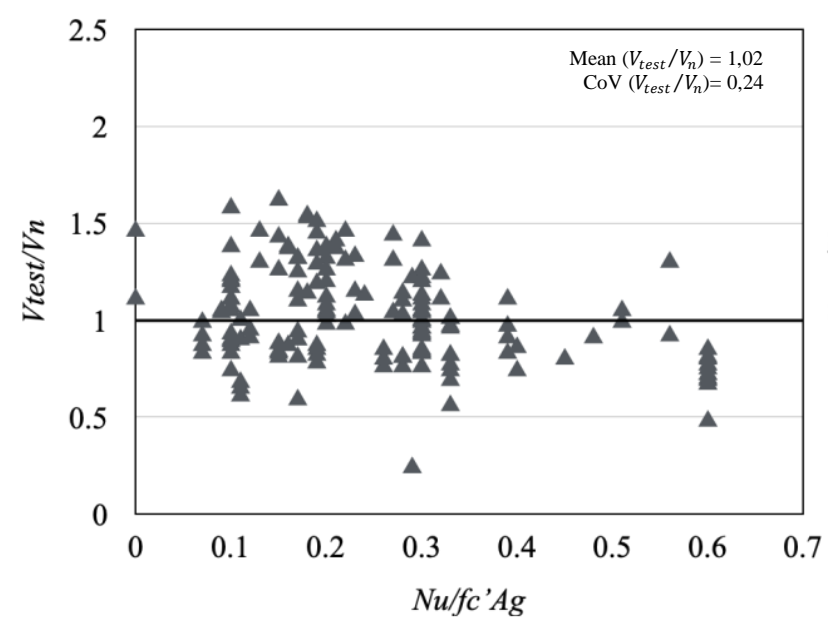

(c) Method in ACI 318-19 $V_{n, A C I 1}$ according to existing data

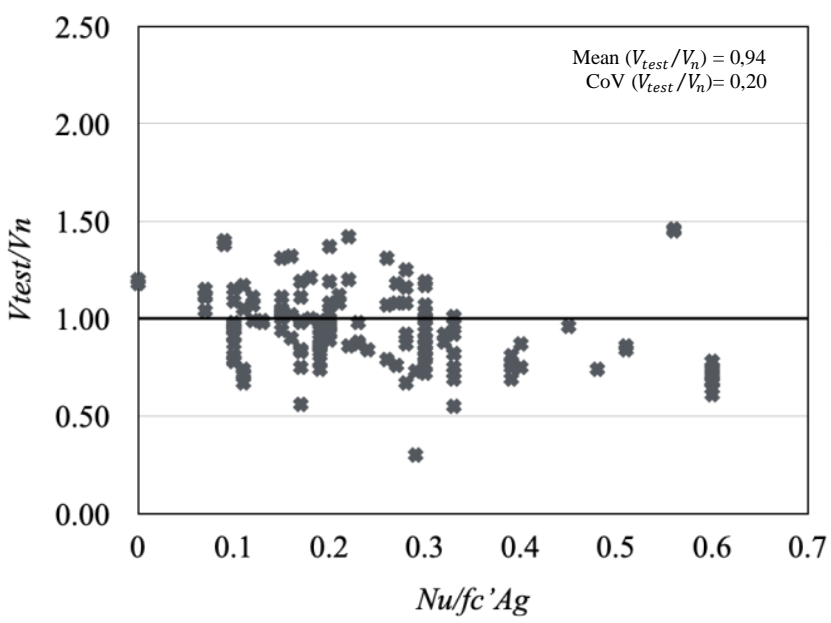

(e) Method in Sezen's Model $V_{n \text {,sezen }}$ according to existing data

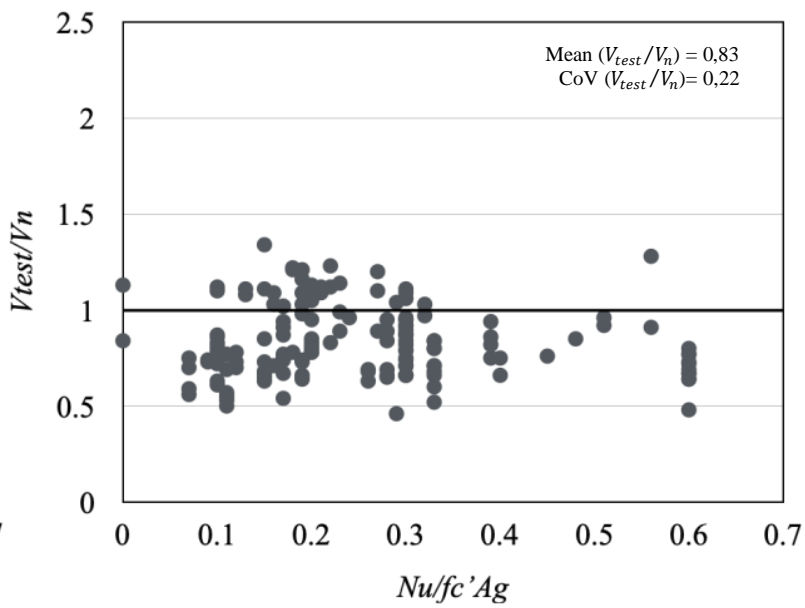

(b) Method in SNI 2847-2019 $V_{n, S N I 2}$ according to existing data

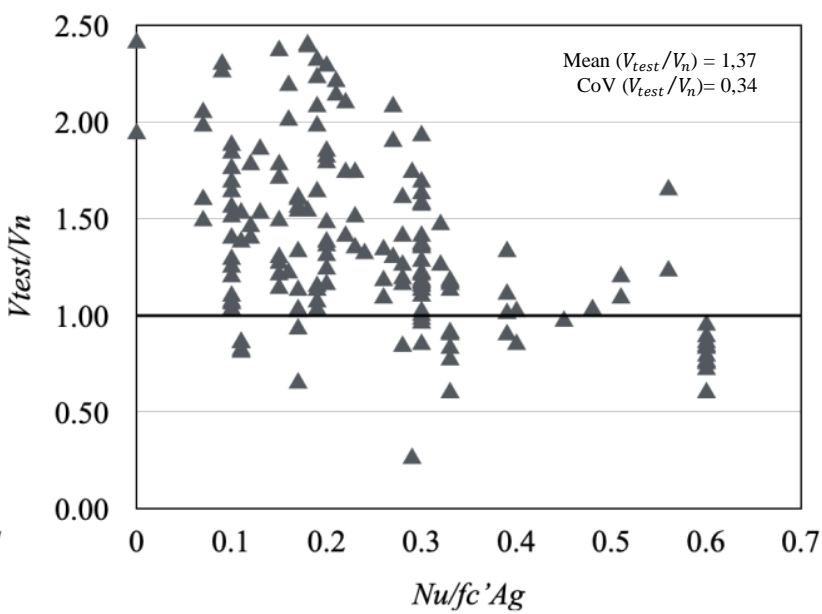

(d) Method in ACI 318-19 $V_{n, A C I 2}$ according to existing data

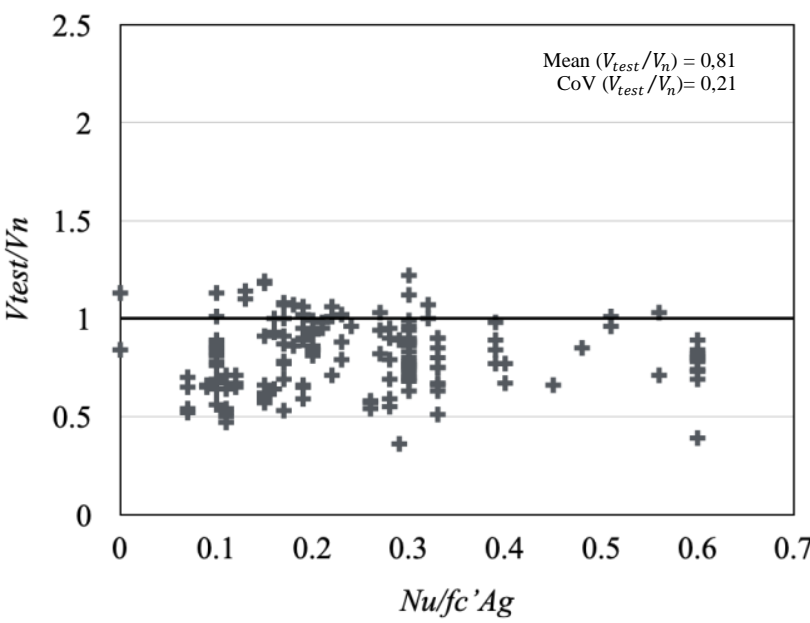

(f) Method in Alrasyid's Model $V_{n \text {,alrasyid }}$ according to existing data

Figure 5. Variations of measured to calculated strength ratio versus axial-load ratio according to existing data: (a) Method in SNI 2847-2019 $V_{n, S N I I}$ [1]; (b) Method in SNI 2847-2019 $V_{n, S N I 2}$ [1]; (c) Method in ACI 318-19 $V_{n, A C I I}$ [2];

(d) Method in ACI 318-19 $V_{n, A C I 2}$ [2]; (e) Method in Sezen's Model $V_{n, \text { sezen }}$ [12]; (f) Method in Alrasyid's Model $V_{n, \text { alrasyid }}[11]$. 


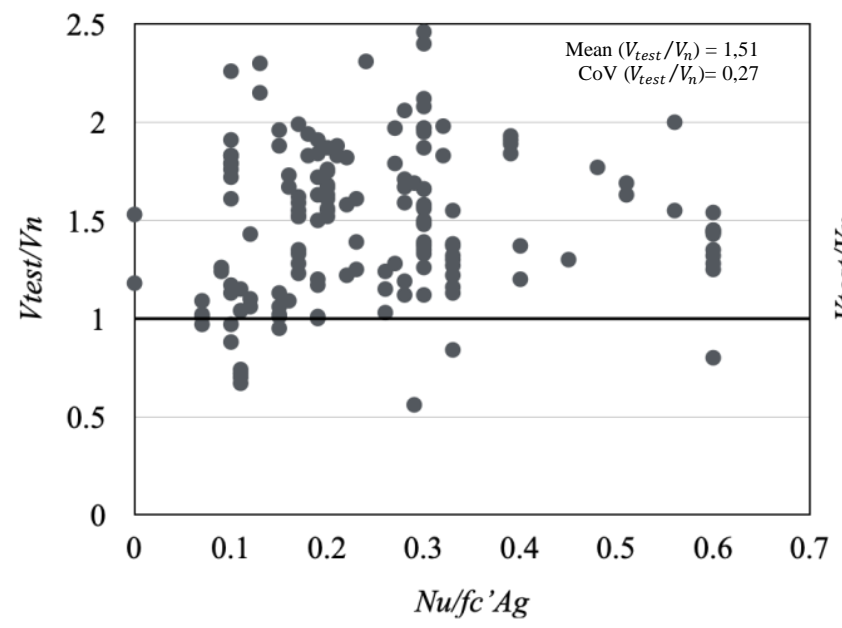

(a) Method in SNI 2847-2019 $V_{n, S N I 1}$ according to maximum limit

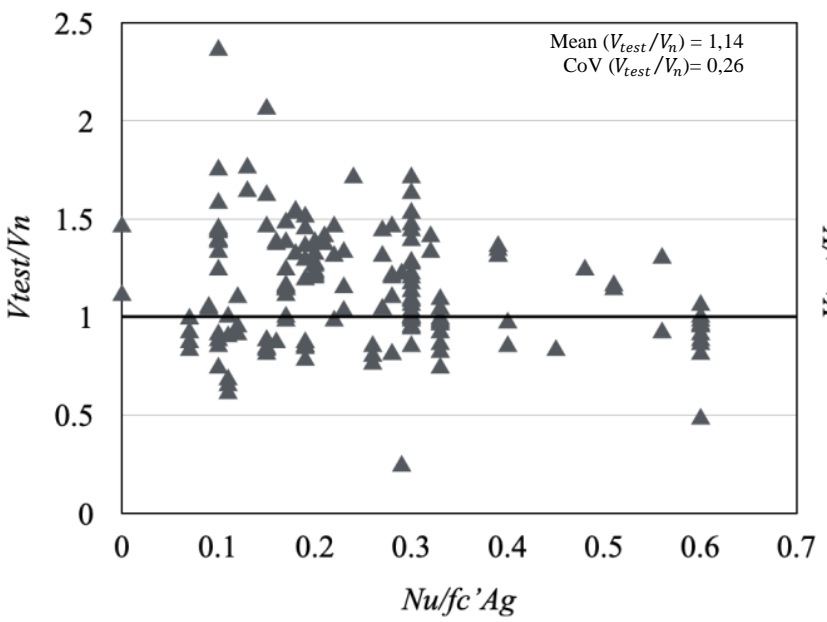

(c) Method in ACI 318-19 $V_{n, A C I 1}$ according to maximum limit

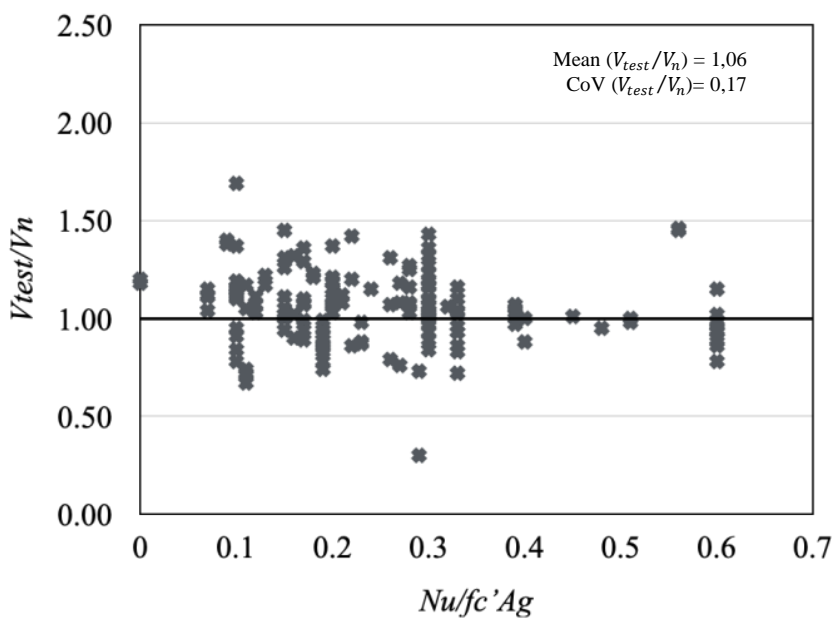

(e) Method in Sezen's Model $V_{n \text {,sezen }}$ according to maximum limit

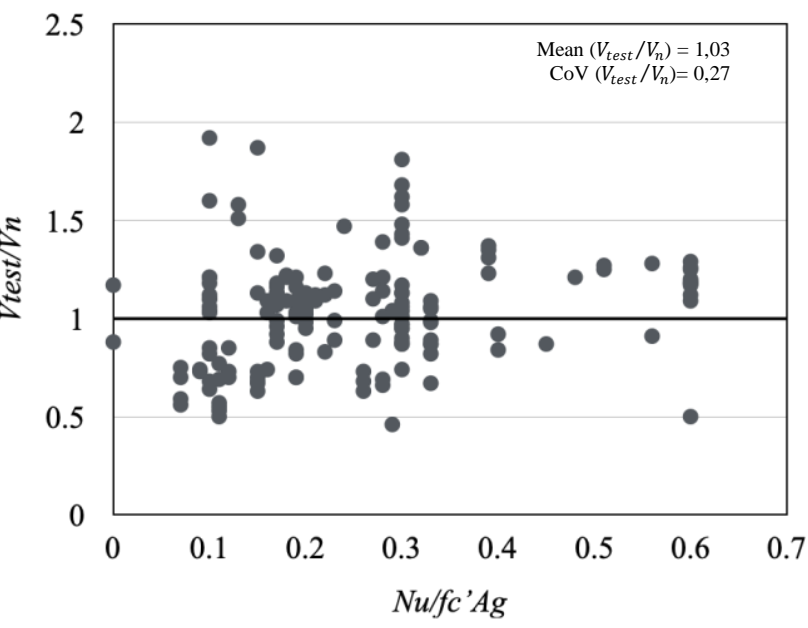

(b) Method in SNI 2847-2019 $V_{n, S N I 2}$ according to maximum limit

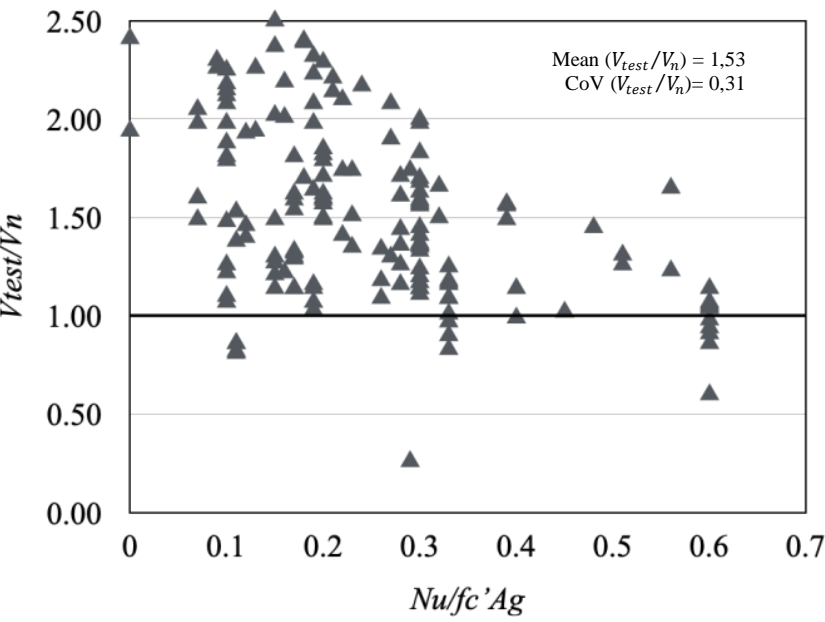

(d) Method in ACI 318-19 $V_{n, A C I 2}$ according to maximum limit

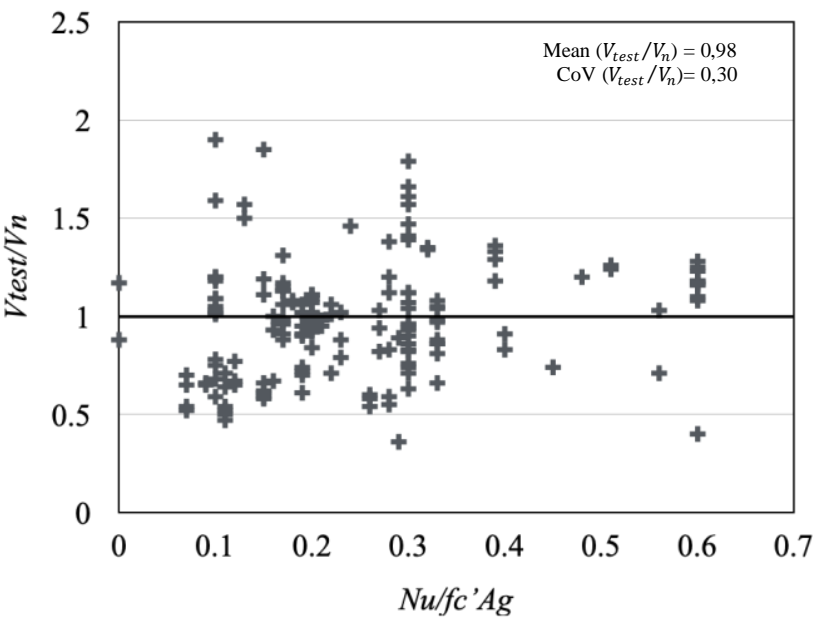

(e) Method in Sezen's Model $V_{n \text {,sezen }}$ according to maximum limit

Figure 6. Variations of measured to calculated strength ratio versus axial-load ratio according to maximum limit: (a) Method in SNI 2847-2019 $V_{n, S N I I}$ [1]; (b) Method in SNI 2847-2019 $V_{n, S N I 2}$ [1]; (c) Method in ACI 318-19 $V_{n, A C I I}$ [2];

(d) Method in ACI 318-19 $V_{n, A C I 2}$ [2]; (e) Method in Sezen's Model $V_{n, \text { sezen }}$ [12]; (f) Method in Alrasyid's Model $V_{n, \text { alrasyid }}[11]$. 
mean can be said to be more precise if the value is more than equal to 1 . Hence, the evaluation model can be said to be more conservative if the $\mathrm{CoV}$ value is low and the mean is more than equal to 1 .

As can be seen in Table 3, for normal strength according to the data, the mean ratio of measured to calculated shear strength and its coefficient of variation are 1.30 and $0.29,1.08$ and $0.26,1.04$ and $0.27,1.57$ and 0.33 , 1.02 and $0.20,0.76$ and 0.25 for the simplified SNI 3847 [1], detailed SNI 2847 [1], simplified ACI 318 [2], detailed ACI 318 [2], Sezen [12], and Alrasyid [11], respectively. From these results, it can be seen that Sezen's model [12] has the best precision; however, for popular models, simplified ACI 318 [2] is relatively conservative than SNI 2847 [1]. Whereas, the normal strength within the maximum limit, there are no significant results because only a few normal strength data exceed the material limitation.

Furthermore, the simplified SNI 2847 [1] is relatively conservative in high strength according to data. On the other hand, for high strength within the maximum limit, it can be seen that Sezen's model [12] has the best precision. In addition, the simplified ACI 318 [2] and Alrasyid's model [11] also have good precision results.

Figures 3-6 plot the ratio of measured shear strength, $V_{\text {test }}$, to the calculated shear strengths, $V_{n, S N I I}, V_{n, S N I 2}, V_{n, A C I 1}$, $V_{n, A C I 2}, V_{n, \text { sezen }}, V_{n, \text { alrasyid }}$ versus the shear span-to-depth ratio and axial-load ratio, respectively. Figures 3-4 show the relationship between aspect ratio and shear strength models. All shear strength models indicate a declining data together with the increase in aspect ratio, except Sezen's model [12]. Therefore, the shear strength is significantly influenced by the shear span-to-depth ratio because the greater the aspect ratio value, the decreases the shear strength value.

The ratio between the measured shear strength to nominal shear strength decreases as the increasing of axial load ratio. These graphics is also exhibited in the relation of axial load ratio and the ratio between the measured shear strength in several models. The data trend to show that shear strength decreases with an increasing axial-load ratio, except the Alrasyid's model. The relations between axial load ratio and the ratio of the measured shear strength to the shear strength prediction are plotted in Figures 5-6.

When determining the concrete shear strength of RC Columns the size effect modification factor $\left(\lambda_{s}\right)$ is also considered at detailed ACI 318 [2]. However, this size effect modification factor is not considered at SNI 2847 [1]. The results have shown that using the size effect modification factor is not affected because the value is close to 1 , within the minimum results of size effect is 0.83 and the maximum size effect is 1.1 in both normal and high strength RC columns.

\section{CONCLUSIONS}

The observed results of collected experimental data of 162 RC columns were measured and evaluated by popular models from SNI 2847-2019 and ACI 318-19, and other experimental models such as Sezen 2002 and Alrasyid 2015. The results from the evaluations show that the simplified SNI and the detailed ACI are more conservative compared to other nominal shear strength equations. The detailed SNI has less conservative, conversely, the simplified ACI has a good precision under the maximum limit of material used. From other experimental models, Sezen's model is relatively conservative in normal strength, whereas, Alrasyid's model also has a good precision for high strength according to the maximum limit of material used. Moreover, the size effect modification factor $\left(\lambda_{s}\right)$ is included in detailed ACI for evaluating the concrete shear strength of RC Columns. The results show that the utilization of the size effect modification factor is not affected because the value is close to 1 .

\section{NOTATION}

$A_{g} \quad=$ gross area of section, $\mathrm{mm}^{2}$, the area of the concrete only and does not include the area of the void(s);

$A_{v} \quad=$ area of shear reinforcement within spacing $\mathrm{s}, \mathrm{mm}^{2}$;

$a \quad=$ shear span, $\mathrm{mm}$;

$b_{w} \quad=$ width of column, mm;

$d \quad=$ effective depth of column, $\mathrm{mm}$;

$f_{c}{ }^{\prime} \quad=$ specified compressive strength of concrete, $\mathrm{MPa}$;

$f_{y t}=$ specified yield strength of transverse reinforcement, $\mathrm{MPa}$;

$N_{u}$ = factored axial force normal to cross section, $\mathrm{N}$;

$s \quad=$ spacing of transverse reinforcement, $\mathrm{mm}$;

$V_{c} \quad=$ nominal shear strength provided by concrete, $\mathrm{N}$;

$V_{\text {test }}=$ measured shear strength of column, $\mathrm{N}$;

$V_{n} \quad=$ nominal shear strength, $\mathrm{N}$;

$V_{s}=$ nominal shear strength provided by shear reinforcement, $\mathrm{N}$;

$\alpha=$ factor to account for column aspect ratio;

$\lambda=$ modification factor to reflect the reduced normal weight concrete of the same compressive strength;

$\lambda_{s} \quad=$ the size effect factor used to modify shear strength based on the effects of member depth;

$\rho_{w}=$ ratio of $A_{s}$ to $b_{w} . d$, where $A_{s}$ is area of nonprestressed longitudinal tension reinforcement.

\section{REFERENCES}

[1] Persyaratan Beton Struktural untuk Bangunan Gedung (SNI 2847 - 2019). 2019.

[2] American Concrete Institute (ACI) Committee 318, Building Code Requirements for Reinforced Concrete (ACI 318-08) and Commentary (ACI 318R-08). 2019.

[3] Z. Pan and B. Li, "Truss-Arch Model for Shear Strength of Shear-Critical Reinforced Concrete Columns," Journal of Structural Engineering, vol. 139, no. 4, pp. 548-560, 2013, doi: 10.1061/(asce)st.1943-541x.0000677.

[4] H. Aoyama, Design of modern highrise reinforced concrete structures, vol. 3. 2001.

[5] M. Maruta, "Shear Capacity of Reinforced Concrete Column using High Strength Concrete."

[6] N. Sakaguchi, K. Yamanobe, Y. Kitada, T. Kawachi, and S. Koda, "Shear Strength of High-Strength Concrete Members," in SP-121: Second International Symposium on High-Strength Concrete, 1990, pp. 157-178.

[7] H. Kuramoto and K. Minami, "Experiments on The Shear Strength of Ultra-High Strength Reinforced Concrete Columns." 
[8] F. Watanabe and T. Kabeyasawa, "Shear Strength of RC Members with High-Strength Concrete," in Special Publication, 1998, vol. 176, pp. 379-396.

[9] C. Jin, Z. Pan, S. Meng, and Z. Qiao, "Seismic Behavior of Shear-Critical Reinforced High-Strength Concrete Columns," Journal of Structural Engineering, vol. 141, no. 8, p. 04014198, 2015, doi: 10.1061/(asce)st.1943-541x.0001167.

[10] Y. C. Ou and D. P. Kurniawan, "Effect of axial compression on shear behavior of high-strength reinforced concrete columns," ACI Structural Journal, vol. 112, no. 2, 2015, doi: $10.14359 / 51687300$.

[11] H. Alrasyid, Seismic Shear Behavior of HighStrength Reinforced Concrete Columns, no. July. 2015.

[12] H. Sezen, "Seismic Behavior and Modeling of Reinforced Concrete Building Columns.," 2002.

[13] A. C. Lynn, "Seismic Evaluation of Existing Reinforced Concrete Building Columns," Journal of Chemical Information and Modeling, vol. 53, no. 9, pp. 21-25, 2001, [Online]. Available: http://www.elsevier.com/locate/scp.

[14] H. Umehara and J. Jirsa, "Shear strength and deterioration of short reinforced concrete columns under cyclic deformations," Pmfsel Rep. No. 82-3, no. 82 , p. 273, 1982, [Online]. Available: http://fsel.engr.utexas.edu/publications/docs/823.pdf.

[15] B. J. Bett, J. O. Jirsa, and R. E. Klingner, Behavior of strengthened and repaired reinforced concrete columns under cyclic deformations. Phil M. Ferguson Structural Engineering Laboratory, University of Texas at ..., 1985.

[16] X. Yan and M. Armen, "Seismic Performance of High-Strength Concrete Columns," Journal of Structural Engineering, vol. 124, no. 3, pp. 241-251, Mar. 1998, doi: 10.1061/(ASCE)07339445(1998)124:3(241).

[17] H. Ousalem, T. Kabeyasawa, and A. Tasai, "Evaluation of ultimate deformation capacity at axial load collapse of reinforced concrete columns," 13th World Conference on Earthquake Engineering, no. 370 , p. 11, 2006, [Online]. Available: http://www.iitk.ac.in/nicee/wcee/article/13_370.pdf.

[18] M. Yoshimura and T. Nakamura, "Axial collapse of reinforced concrete short columns," PEER Rep., vol. 21, pp. 187-198, 2002.

[19] H. Ramirez and J. Jirsa, "EFFECT OF AXIAL LOAD ON SHEAR BEHAVIOR OF SHORT RC COLUMNS UNDER CYCLIC LATERAL DEFORMATIONS," June, pp. 1-22, 1980.

[20] J. K. Wight and M. A. Sozen, "Shear Strength Decay in Reinforced Concrete Columns Subjected to Large," Res. Project Report, Univ. Illinois., no. August, p. 312, 1973.

[21] C. Yalcin, Seismic evaluation and retrofit of existing reinforced concrete bridge column. $\mathrm{Ph}$. D. Thesis. University of Ottawa, Canada, 1997.

[22] A. Ikeda, "A list of past experimental results of reinforced concrete columns," ep., Train. Inst. Eng. Teach. Yokohama Natl. Univ., Build. Res. Institute, Minist. Constr. Tokyo, Japan., 1968.
[23] H. Umemura and T. Endo, "A list of past experimental results of reinforced concrete columns," Rep., Umemura Lab. Tokyo Univ., Build. Res. Institute, Minist. Constr. Tokyo, Japan., 1970.

[24] S. Kokusho, "A list of past experimental results of reinforced concrete columns," Rep., Build. Res. Institute, Minist. Constr. Tokyo, Japan., 1964.

[25] S. Kokusho and M. Fukuhara, "A list of past experimental results of reinforced concrete columns," Rep., Kokusho Lab. Tokyo Ind. Univ., Build. Res. Institute, Minist. Constr. Tokyo, Japan., 1965.

[26] A. Maruta, High-strength concrete. 2008.

[27] S. Takami and K. Yoshioka, "Shear strength of RC columns using high-strength concrete," in Summaries of Technical Papers of Annual Meeting, Structures IV, Architectural Institute of Japan, Tokyo, Japan, 1997, pp. 25-26.

[28] Y. Takaine, S. Nagai, M. Maruta, and N. Suzuki, "Shear Performance of RC Column Using 200 N/mm2 Concrete," in Summaries of Technical Papers of Annual Meeting, Structures IV, Architectural Institute of Japan, Tokyo, Japan, 2010, pp. 295-296.

[29] H. Kuramoto and K. Minami, "Experiments on the shear strength of ultra-high strength reinforced concrete columns," in Proceedings of the Tenth World Conference on Earthquake Engineering, 1992, pp. 3001-3006.

[30] Y. Shinohara, T. Kubota, and S. Hayashi, "Shear Crack Behaviors of Ultra-High-Strength Concrete Columns (Part 1 and Part 2)," in Summaries of Technical Papers of Annual Meeting, Structures IV, Architectural Institute of Japan, Tokyo, Japan, 2008, pp. 605-608.

[31] N. Akihiko, H. Kuramoto, and M. Koichi, "Shear Strength and Behavior of Reinforced Concrete Columns Using High-Strength Concrete of $\sigma \mathrm{B}=1200$ kgf/cm2 (Part 1 and Part 2)," Proc. Archit. Inst. Japan, pp. 53-60, 1990.

[32] M. Sibata, H. Kanasugi, M. Uwada, H. Ooyama, and Y. Yamashita, "Experimental Study on Shear Behavior of Reinforced Concrete Columns Using High-Strength Shear Reinforcement of $8000 \mathrm{kgf} / \mathrm{cm} 2$ Grade (Part 4)," in Summaries of Technical Papers of Annual Meeting, Structures IV, Architectural Institute of Japan, 1997, pp. 7-8. 
